\title{
CIVIL LIABILITY FOR ARTIFICIAL INTELLIGENCE PRODUCTS VERSUS THE SUSTAINABLE DEVELOPMENT OF CEECs: WHICH INSTITUTIONS MATTER?*
}

\section{INTRODUCTION}

Over the next decade, Artificial Intelligence (AI) may significantly transform our lives, from using virtual personal assistants to travelling in selfdriving vehicles. ${ }^{1} \mathrm{AI}$ also has the power to overcome the physical limitations of capital and labour and to create new sources of value and growth. ${ }^{2}$ Moreover, $\mathrm{AI}$ has the potential to change the status quo and create new business opportunities, shift surpluses for businesses, change national comparative economics $^{3}$ and to significantly transform the world economy, ${ }^{4}$ as well as the economy of the Central and Eastern European Countries (CEECs). ${ }^{5}$ However, scholars and experts stress concern about sustainable development ${ }^{6}$ due to the possibility of mass unemployment, ${ }^{7}$ the military threat of autonomous weapons,${ }^{8}$ and

\footnotetext{
* Previous versions of this article were presented at World Interdisciplinary Network for Institutional Research Conference 'Institutions and the future of global capitalism', 14-17 September 2018, Hong-Kong and at the conference 'Institutions in the theory and practice. Past present - future', 25-26 September 2019, Poznań.

${ }^{1}$ European Commission (2020a). White paper on Artificial Intelligence - A European approach to excellence and trust. COM(2020)65 final; European Commission (2018a). Commission Staff Working Document, Liability for emerging digital technologies, SWD (2018) 137 final; Accompanying the document Communication from the Commission to the European Parliament, the European Council, the European Economic and Social Committee and the Committee of the Regions, on the Mid-Term Review on the implementation of the Digital Single Market Strategy, A connected Digital Single Market for All. COM(2017)228 final; European Commission (2018b). The Age of Artificial Intelligence, Towards a European Strategy for Human-Centric Machines. EPSC Strategic Notes, Issue 29.

2 Accenture (2016).

3 McKinsey Global Institute (2013).

4 European Commission (2018a), (2018b).

5 Central and Eastern European Countries (CEECs) is an OECD term.

6 According to Borys (2011), the concept of integrated order, which is a target system for sustainable development, involves achieving social, institutional, political, economic, environmental and spatial order.

7 Arntz et al. (2016).

8 The Economist (2018).
} 
problems with the redistribution of wealth. ${ }^{9}$ On the other hand, the European Commission (Commission) argues that AI can lead to fewer fatalities on roads, smarter use of resources, better environmental protection, increasing the efficiency of framing, improved healthcare and a more competitive manufacturing sector. ${ }^{10}$

The Commission pinpoints that the current and future sustainable development of the European Union (EU) Member States such as the CEECs, increasingly depends on the value created by data and AI in key applications of the data economy. ${ }^{11}$ However, the use of AI on a large scale comes with both threats and opportunities. The Commission highlights that lack of trust is holding back a much broader uptake of AI than at present. ${ }^{12}$ That is why the goal of the Commission is to develop AI grounded on ethical and societal values, fundamental rights and freedoms. ${ }^{13}$ In order to achieve this goal, in the White Paper on Artificial Intelligence - A European approach to excellence and trust or in Report on the safety and liability implications of Artificial Intelligence, the Internet of Things and robotics the Commission stresses the necessity of new regulatory framework, especially for high-risk AI. ${ }^{14}$ Nevertheless, the biggest problem for the EU is outdated law which is not suitable for solving the contemporary problems and threats ${ }^{15}$ posed by AI. If the damage resulting from AI usage occurs, victims will seek compensation. In the EU, only strict liability of producers for defective products is harmonized at the EU level, while all other liability regimes are regulated by the Member States like the CEECs themselves. ${ }^{16}$ Furthermore, in the literature on the subject, there is a high-stakes debate about the legal status of AI, about who should bear the liability for AI damages, and which liability rules will lead to welfare optimization. ${ }^{17}$

The aim of this paper is to undertake a meta-analysis of the EU and CEECs' civil liability institutions in order to find out if they are ready for the AI race. Particular focus is put on ascertaining whether these liability institutions will protect consumers and entrepreneurs, and ensure undistorted competition. In line with the aforementioned, the authors investigate whether the civil liability institutions such as the Product Liability Directive (EU) or civil codes (CEECs), are based on regulations that can be adapted to the new generation

${ }^{9}$ Amiot (2016).

${ }_{10}$ European Commission (2020a), (2018a).

${ }^{11}$ European Commission (2020a).

12 European Commission (2020a); European Commission (2020b). Report from the Commission to the European Parliament, the Council and the European Economic and Social Committee. Report on the safety and liability implications of Artificial Intelligence, the Internet of Things and robotics. $\operatorname{COM}(2020) 64$ final.

${ }^{13}$ European Commission (2020a).

${ }^{14}$ European Commission (2020a), (2020b).

15 Schwab, Davis (2018).

${ }^{16}$ European Commission (2019). Liability for Artificial Intelligence and other emerging digital technologies. Report from the Expert Group on Liability and New Technologies - New Technologies Formation.

${ }^{17}$ Polinsky, Rubinfeld (1988). 
of robots which will be equipped with learning abilities and have a certain degree of unpredictability in their behaviour. The conclusion presented in the paper is drawn on the basis of a review of the current literature and research on national and European regulations. The primary contribution that this article makes is to advance the stream of the research concerning the concepts of AI liability for damages and personal injuries. A second contribution is to show that current civil liability institutions of the EU as well as CEECs are not sufficiently prepared for addressing the legal issues that will start to arise when self-driving vehicles or autonomous drones begin operating in fully autonomous modes and possibly cause property damage or personal injuries.

\section{THE EU CIVIL LIABILITY INSTITUTIONS}

According to the Commission, AI is 'a collection of technologies that combine data, algorithms and computing power'18 and 'refers to systems that display intelligent behaviour by analysing their environment and taking actions - with some degree of autonomy - to achieve specific goals. ${ }^{19}$ AI systems may act in unpredictable ways, for example, via a self-learning system that acts autonomously and independently from the designer, programmer and manufacturer.$^{20}$ Moreover, current American or the EU jurisdictions do not allow for AI entities to be sued for their acts or omissions, ${ }^{21}$ or for their criminal liability. ${ }^{22}$ However, the Commission argues that the EU has a 'robust and reliable safety and product liability regulatory framework and a robust body of safety standards, complemented by national non-harmonized liability legislation'. ${ }^{23}$ Furthermore, European civil liability rules should ensure, on the one hand, that victims of damage caused by AI products get compensation, and on the other hand, should provide economic incentives, for example, to encourage the liable producer of AI to avoid causing such damage.

In the opinion of the Commission, the EU safety and product liability regulatory framework has to be flexible when applied to AI products. ${ }^{24}$ It should also continue to respect key fundamental principles of the EU, such as the defence of democracy, the protection of European values and data privacy, sustainable development, and fostering innovation and competition in the EU economy. Moreover, the behaviour of AI may be difficult to predict, and this

18 European Commission (2020a): 2.

19 European Commission (2018c). Communication from the Commission to the European Parliament, the European Council, the European Economic and Social Committee and the Committee of the Regions, Artificial intelligence for Europe. COM(2018)237 final: 2.

20 Maldonado (2018).

21 United States v. Athlone Indus., Inc.

22 Lea (2015).

23 European Commission (2020b): 1.

24 European Commission (2018b). 
may lead to situations where the damage caused by AI operating with a certain degree of autonomy cannot be linked to a defect or a human wrongdoing. ${ }^{25}$ Furthermore, according to the Commission, the following institutions are particularly important for the sustainable development of the European economy based on AI solutions: ${ }^{26}$

- Council Directive 85/374/EEC of 25 July 1985 on the approximation of the laws, regulations and administrative provisions of the Member States concerning liability for defective products (Product Liability Directive), the purpose of which is to determine the producer's liability for damage to the consumer's health or their property caused by a defect in the producer's products;

- Directive 2001/95/EC of the European Parliament and of the Council of 3 December 2001 on general product safety (Product Safety Directive), the purpose of which is to ensure that products offered on the EU market are safe;

- Directive 2006/42/EC of the European Parliament and of the Council of 17 May 2006 on machinery, and amending Directive 95/16/EC, the purpose of which is to ensure the protection of the health and safety of people and pets due to the risks arising from the use of machinery.

The preamble of the Product Liability Directive introduced the concept of strict liability with regard to AI producers, 'whereas liability without fault on the part of the producer is the sole means of adequately solving the problem'. In the case of physical or material damage caused by AI products (such as selfdriving vehicles), the injured party (for example an owner) is entitled to compensation only if he or she proves that the damage is due to a defect in the AI product (that for example self-driving vehicles did not provide the safety that the public, such as the owner, is entitled to expect), and that there is a causal link between the defective AI products (such as self-driving vehicles) and the damage ${ }^{27}$ According to the Commission, product safety and liability legislation is necessary to enable European societies, in particular businesses and consumers, to benefit from AI, and to help protect consumers, entrepreneurs and undistorted competition. ${ }^{28}$

However, are the civil liability institutions of the EU ready for the AI race, for example in the form of self-driving cars or drones, which may lead to conflict between AI manufacturers, designers, programmers, owners, users, operators and third parties? An autonomous drone (unmanned aircraft) ${ }^{29}$ may cause serious property damage or personal injuries by falling to the ground or colliding inair with another flying vessel. The Commission argues that autonomous drones are 'unmanned aircrafts' and thus may be covered by the national legislation of Member States and international conventions pertaining aircraft. ${ }^{30}$ In such

25 European Commission (2018a).

${ }^{26}$ European Commission (2018c).

27 European Commission (2020b).

28 European Commission (2018d).

${ }^{29}$ According to Article 3 para. 30 of the Regulation (EU) 2018/1139 'unmanned aircraft' means any aircraft operating or designed to operate autonomously or to be piloted remotely without a pilot on board.

30 European Commission (2018a). 
situations, autonomous drones will be subject to a strict liability regime and their operator will be liable for damage. Moreover, Regulation (EU) 2018/1139 $9^{31}$ applies to unmanned aircraft. According to Annex IX point 1.1 of this regulation, the operator of an unmanned aircraft has to be aware of national regulations relating to safety, privacy, data protection, liability, insurance, security, and environmental protection. Furthermore, 'an unmanned aircraft must be designed and constructed so that it is fit for its intended function, and can be operated, adjusted and maintained without putting persons at risk.' It is important to highlight that in the EU, in line with safety regulations, ${ }^{32}$ the produc$\mathrm{ers}^{33}$ of autonomous drones may also be liable for damage caused by a defect in these unmanned aircraft. If an autonomous drone is found to be defective and causes death, personal injury, material damage or destruction above EUR500 to an item of property for private use or consumption, the producers of the said drone will be liable, regardless of their fault. AI products ${ }^{34}$ such as unmanned aircraft or self-driving vehicles may be considered to be defective, according to Article 6 of the Product Liability Directive, when these items do not provide the expected safety. The Commission stresses that the strict liability of producers, for example, for damage caused by autonomous drones or self-driving vehicles, represents a powerful tool for the protection of injured persons (consumers or entrepreneurs) ${ }^{35}$ However, the allocation of liability for damage caused by AI products may be unfair or inefficient on the basis of 'old' European civil liability institutions, such as the Product Liability Directive. ${ }^{36}$

Self-driving vehicles ${ }^{37}$ (autonomous cars), like autonomous drones, may cause serious damage when operating in auto-pilot mode, which that may result in property damage or personal injury. The Commission argues that the key components of the civil liability regime for self-driving vehicles are the national, non-harmonized liability legislation of Member States, which are applicable to

${ }^{31}$ Regulation (EU) 2018/1139 of the European Parliament and of the Council of 4 July 2018 on common rules in the field of civil aviation and the establishing of a European Union Aviation Safety Agency, and in amending Regulations (EC) No 2111/2005, (EC) No 1008/2008, (EU) No 996/2010, (EU) No 376/2014 and Directives 2014/30/EU and 2014/53/EU of the European Parliament and of the Council, and repealing Regulations (EC) No 552/2004 and (EC) No 216/2008 of the European Parliament and of the Council and Council Regulation (EEC) No 3922/91.

32 Directive 2001/95/EC of the European Parliament and of the Council of 3 December 2001 on general product safety.

33 According to Article 3 of the Defective Product Directive: "Producer" means the manufacturer of a finished product, the producer of any raw material or the manufacturer of a component part and any person who, by putting his name, trade mark or other distinguishing feature on the product presents himself as its producers.'

${ }^{34}$ According to Article 2 of the Defective Product Directive: “product” means all movables, with the exception of primary agricultural products and game, even though incorporated into another movable or into an immovable. "Products" includes electricity.'

${ }^{35}$ European Commission (2018d). Evaluating of Council Directive 85/374/EEC on the approximation of laws, regulations and administrative provisions of the Member States concerning liability for defective products.

36 European Commission (2019).

${ }^{37}$ According to the European Commission (2018a), self-driving vehicles are 'motor vehicles equipped with systems that allow operating the vehicle without human intervention either partially, or completely.' 
motor vehicles..$^{38}$ Furthermore, under the preamble of the Directive 2009/103/ EC $^{39}$ (Motor Vehicle Directive), all Member States must ensure that civil liability for the use of vehicles will be covered by insurance. The victims of such accidents will thus have a direct claim for compensation for the insurer covering the person responsible for civil liability. However, the Motor Vehicle Directive does not cover accidents caused by self-driving vehicles. The Commission highlights that in the case of an accident caused by a self-driving vehicle, liability for damage may be allocated to the driver/ holder of the vehicle or to the producers under national liability legislation. ${ }^{40}$ However, Article 7 of the Product Liability Directive allows the producers of AI, such as self-driving vehicles or autonomous drones, to escape liability for defective AI products if they prove: i) that it is probable that the defect did not exist when the product was put into circulation; ii) that the product was not manufactured for sale or for any economic purpose; iii) that the defect is due to compliance with mandatory regulations; or iv) that the state of scientific and technical knowledge at the time of putting the product on the market did not enable the defect to be to discovered.

The Commission argues that a technology-neutral safety legal framework will prevent accidents with AI products. However, if such accidents happen, the liability framework in the EU as well as in the CEECs should ensure compensation for injured persons. ${ }^{41}$ Moreover, Vladeck argues that the EU civil liability institutions are not sufficiently equipped to address the legal issues that will arise when self-driving vehicles or autonomous drones start to operate in fully autonomous mode, without a human in the control loop. ${ }^{42}$ It is very important to highlight the need for implementing the common European framework for civil liability of AI, and for creating a catalogue of possible AI concepts in accordance with the national civil liability institutions.

The European Parliament emphasizes that the current EU civil liability institutions lack sufficient regulations to cover the damage caused by a new generation of robots which will be equipped with learning abilities and which will have a certain degree of unpredictability in their behaviour ${ }^{43}$. Indeed, we already have AI search engines as Google Search and Apple applications like Siri. However, the EU legal framework 'provides a layer of protection that national fault-based liability alone does not provide', ${ }^{44}$ and is extremely important for the protection of consumers, and entrepreneurs, and for ensuring undistorted competition. Moreover, a common European approach to AI

${ }^{38}$ European Commission (2018a).

${ }^{39}$ Directive 2009/103/EC of the European Parliament and of the Council of 16 September 2009 relating to insurance against civil liability in respect of the use of motor vehicles, and the enforcement of the obligation to insure against such liability.

${ }^{40}$ European Commission (2018a).

${ }^{41}$ European Commission (2018d).

${ }^{42}$ Vladeck (2014).

${ }^{43}$ European Parliament (2017). Report with recommendations to the Commission on Civil Law Rules on Robotics (2015/2103(INL); European Parliament (2016). Draft Report with recommendations to the Commission on Civil Law Rules on Robotics (2015/2103(INL).

${ }^{44}$ European Commission (2020b): 12. 
is needed in order to avoid the fragmentation of the single market. ${ }^{45}$ On the other hand, European civil liability institutions such as the Product Liability Directive are based on regulations that cannot be fully adapted to the new generation of robots that will be equipped with learning abilities and have a certain degree of unpredictability in their behaviour. That is why, according to the Commission experts, 'certain adjustments need to be made to EU and national liability regimes' ${ }^{46}$ For example, the Commission experts indicate that 'AI-driven robots in public spaces, should be subject to strict liability for damage resulting from its operation', ${ }^{47}$ and 'A person using a technology which has a certain degree of autonomy should not be less accountable for ensuing harm than if said harm had been caused by a human auxiliary. ${ }^{48}$

\section{THE CIVIL LIABILITY INSTITUTIONS OF THE CEECs}

Under the Treaty of Accession, the CEECs are obliged (from the date of accession) to apply EU law. The principle of the primacy of EU over the CEECs' law does not appear expressis verbis in the treaties, but results from the rulings of the Court of Justice of the EU. ${ }^{49}$ However, the law of tort of EU Member States, such as the CEECs, is non-harmonized (with some exceptions like the Product Liability Directive) and according to the Commission does not contain the necessary liability rules which could be applicable to damage resulting from AI usage.$^{50}$ Meanwhile, for sustainable development of the CEECs, civil liability rules for artificial intelligence products have key significance.

It is important to stress that the more autonomous robots are, the less sufficient are the ordinary rules of liability. Under the current CEECs' civil liability institutions, AI products such as AI robots or self-driving vehicles cannot be held liable per se for acts or omissions that cause damage to third parties. Moreover, the CEECs do not have civil liability institutions such as the French Decree no 2018-211 of 28 March 2018 on experimentation with automated vehicles on public roads, the UK Automated and Electric Vehicles Act 2018 (c 18), Section 2 or the Italian Decree of 28 February 2018 on the testing of connected and automated vehicles on public roads, all of which allow for experimental or regular use of self-driving vehicles, with any damage caused by $\mathrm{AI}$ covered by reference to the general rules or insurance. ${ }^{51}$

In addition, in the literature in the subject there is no common agreement on the concept of AI civil liability. Scholars argue that AI should have the same

${ }^{45}$ European Commission (2020a).

${ }^{46}$ European Commission (2019): 3.

${ }^{47}$ European Commission (2019): 3.

${ }^{48}$ European Commission (2019): 3.

${ }^{49}$ See Costa v. ENEL (1964) Case 6-64; Internationale Handelsgesellschaft mbH $v$ Einfuhrund Vorratsstelle für Getreide und Futtermittel (1970) Case 11-70 or Amministrazione delle Finanze dello Stato v Simmenthal SpA (1977), Case 106-77.

${ }_{50}$ European Commission (2019).

${ }^{51}$ European Commission (2019). 
liability as: i) tools $;{ }^{52}$ ii) wild animals $;{ }^{53}$ iii) legal entities; ${ }^{54}$ iv) electronic persons $;^{55} \mathrm{v}$ ) agents ${ }^{56}$, and vi) companies ${ }^{57}$. The chosen concept of AI civil liability in the CEECs will determine who will be liable for damages and personal injuries caused by AI to third parties (tort liability), and to owners or users of AI (tort and contract liability). According to the CEECs' civil liability institutions, such as civil codes, the following may be liable (see Scheme 1): i) designers, for example for design defects; ii) programmers, for example for software defects; iii) manufacturers, for example for products defects, failure to warn or breach of warranty; iv) operators, for example based on their fault if they operate a drone under dangerous weather conditions or when the required maintenance was not performed; v) owners, for example fault-based for lack of the proper maintenance of AI, or risk-based for the circulation of AI like a self-driving vehicle on public streets; vi) users, for example risk-based, or vii) AI itself based on fault (negligence) or a risk liability regime. Moreover, the liability for the damage and personal injury caused by AI will depend on the status of the AI ownership. AI may be purchased or owned. The legal owner or legal administrator of AI may be responsible for damage to third parties caused by AI.

\section{Scheme 1}

Civil liability of Artificial Intelligence - possible concepts based on CEECs' civil liability

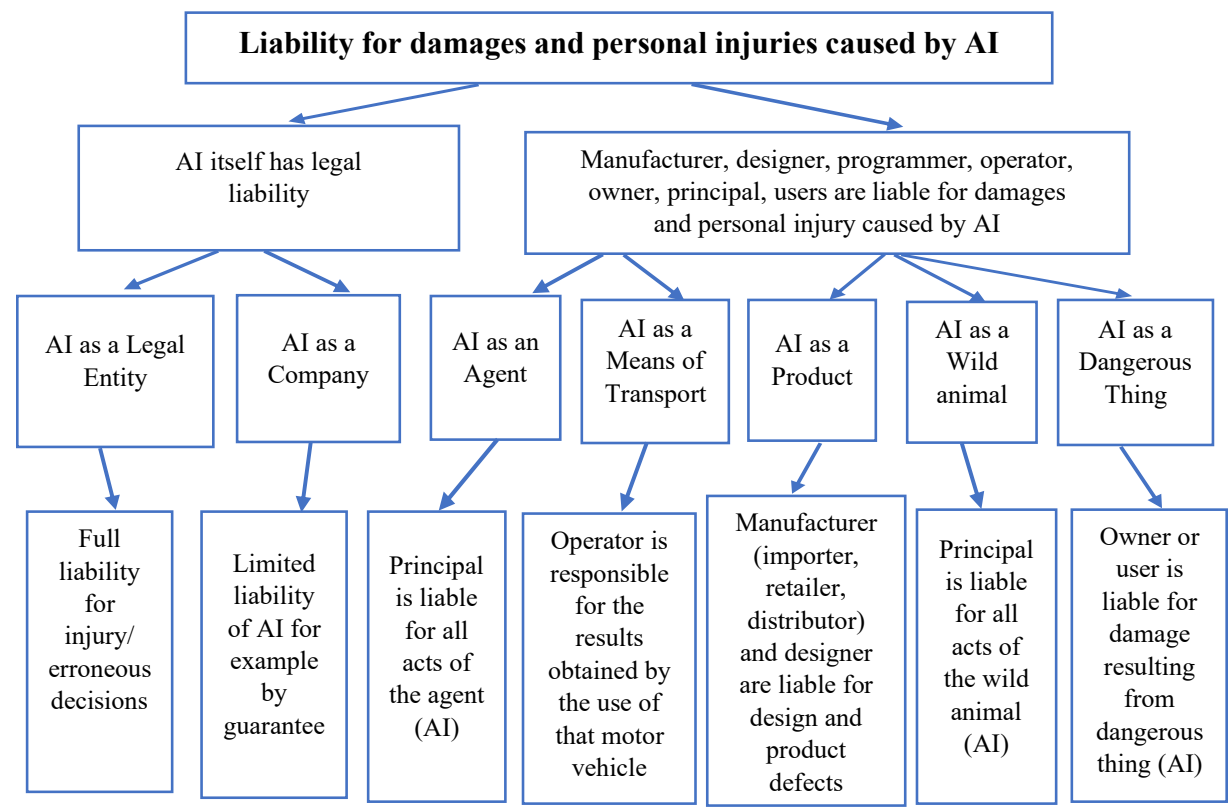

Source: the authors' own work based on meta-analysis of CEECs' civil liability institutions.

\footnotetext{
52 Čerka, Grigienè, Sirbikytè (2015).

${ }^{53}$ Lichtenstein (2017).

54 Vladeck (2014); Lea (2015); Pagallo (2018).

55 European Parliament (2016), (2017).

56 Duggal (2017).

${ }^{57}$ Duggal (2017).
} 
Moreover, according to the meta-analysis of current civil liability institutions of CEECs, AI damage may be fault-based or risk-based (see Table 1): i) if we treat $\mathrm{AI}$ as 'vicariou s a gents', then the driver/ holder of self-driving vehicle will not be liable if they exercise reasonable care when selecting the self-driving vehicle (for example, Article 429 of the Polish Civil Code); ii) if we treat AI as 'a person who requires supervision', then the driver/ holder of self-driving vehicle will not be liable if they fulfil the requirements of their duty to supervise the self-driving vehicle, or if the damage would have been similarly caused in the case of proper conduct of supervision (for example, Article 427 of the Polish Civil Code); iii) if we will treat AI as an 'animal', then the driver/ holder of self-driving vehicle will not be liable if their supervising the self-driving vehicle exercised reasonable care or the damage would have occurred even if this care had been exercised (for example, Section 6:562 of the Hungarian Civil Code); iv) if we treat AI as a 'company or plant', then the driver/ holder of self-driving vehicle will not be liable if the damages occurred as a result of force majeure, or solely by fault of the victim, or by fault of third party for which they are not responsible (for example, Article 2925 of the Czech Civil Code), v) if we treat AI as a 'means of transport', the driver/ holder of the self-driving vehicle may be released from the obligation to compensate for the damage if they prove that they could not have prevented the damage despite having exerted all the efforts which may have been required (for example, Article 2927 of the Czech Civil Code); vi) if we treat $\mathrm{AI}$ as a 'defective product', then a manufacturer (importer, distributor or retailer) who has placed the self-driving vehicle on the market will be liable for damage caused by defectiveness of that product, regardless of fault (for example, Article 1073 of the Croatia Civil Obligation Act or Article 6.292 of the Lithuanian Civil Code) or finally vii) if we treat AI as a 'dangerous thing', then the owner of the self-driving vehicle will be liable for damage resulting from it unless the self-driving vehicle is repossessed by the other person (for example, Article 1064 of the Croatia Civil Obligation Act).

In CEECs, the strict liability regime which may be called liability for dangerousness ${ }^{58}$ is dominant, but the fault-based liability regime is also important. In the case of AI strict liability, attention is paid to the harmful effect caused by the manifestation of a higher risk connected with AI products. In such cases, the driver/ holder of AI, such as a self-driving vehicle, is liable for the damage caused, regardless of whether they violated the civil liability institutions of CEECs, or whether the driver/holder of self-driving vehicle was at fault. Moreover, in cases of AI strict liability for self-driving vehicles, proving causation may be easier for the victim, like in Article 1063 of the Croatian Civil Obligations Act: 'Damage caused in relation to a dangerous thing or dangerous activity shall be considered to result from that thing or activity, unless it has been proved that it did not cause the damage. ${ }^{59}$ However, some liability

\footnotetext{
${ }^{58}$ Koziol (2012).

${ }^{59}$ European Commission (2019): 21.
} 


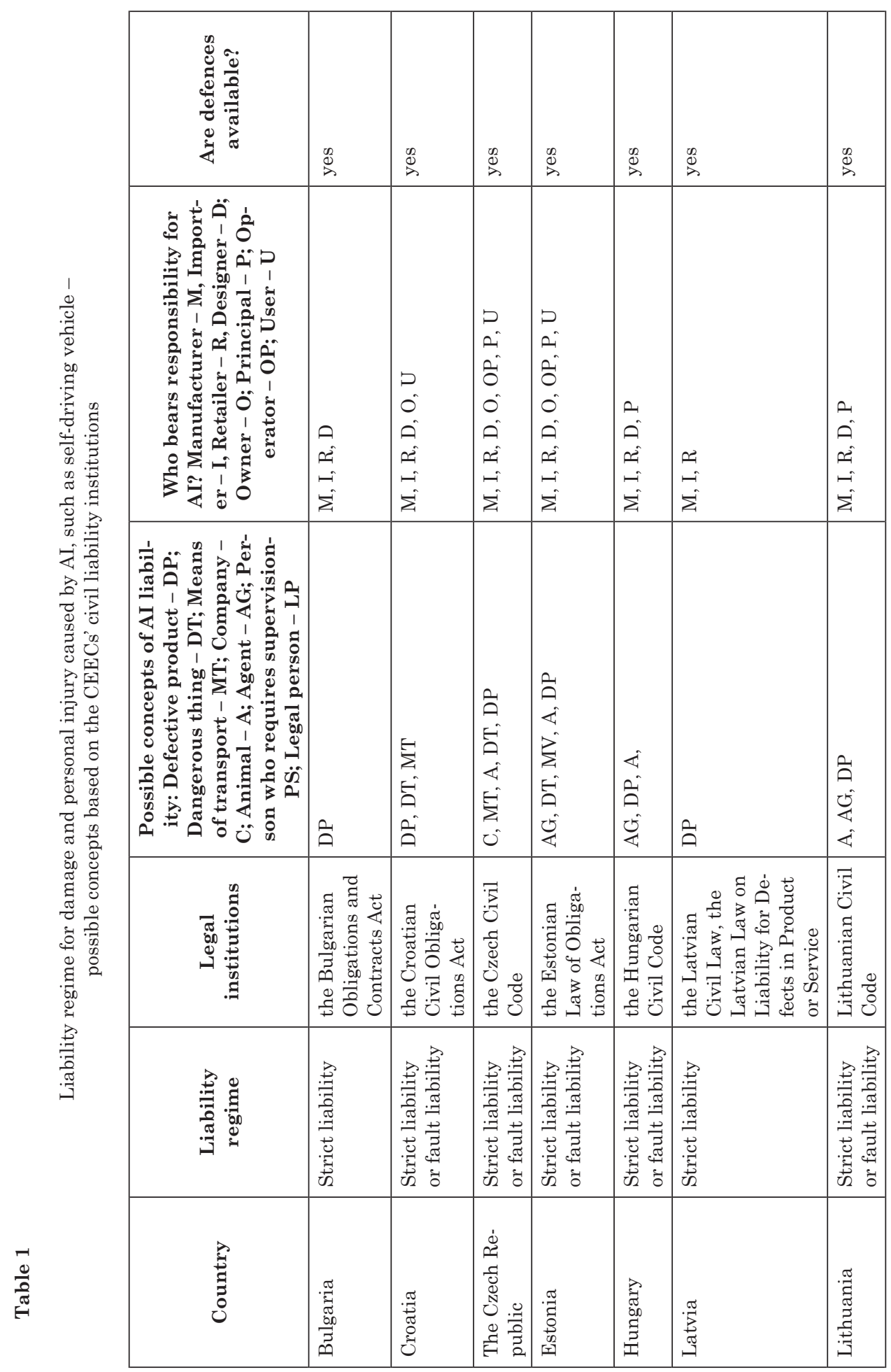




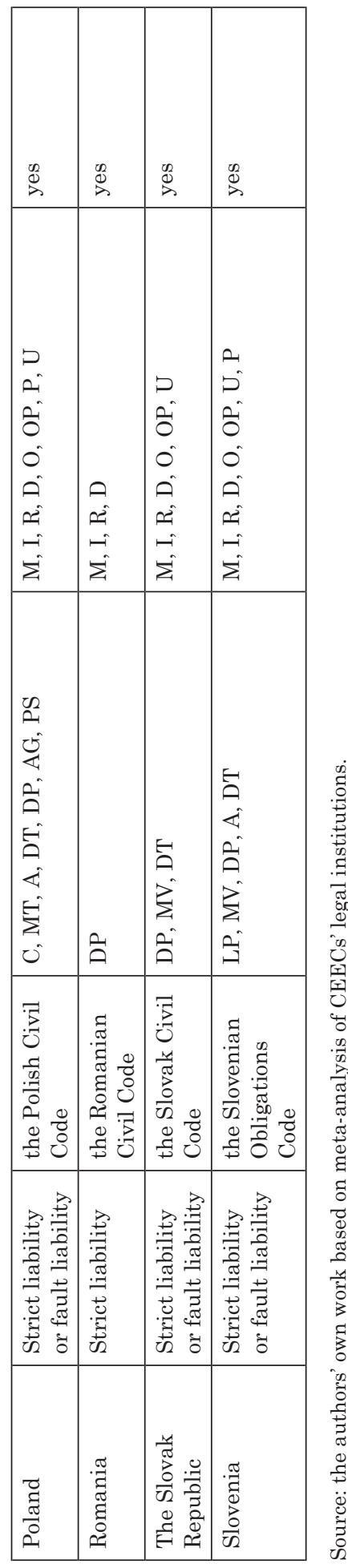


institutions, such as Article $436 \S 2$ of the Polish Civil Code, exclude passengers from protection under strict liability if they are transported without any remuneration or other benefit.

Meanwhile, in the case of AI fault-based liability, attention is paid to the fault of the defendant, for example the driver/ holder of a self-driving vehicle for damage suffered by the victim. It is important to identify the duties of care the perpetrator (for example the driver/ holder of self-driving vehicle) should have discharged, for example upgrading the GPS system of a self-driving vehicle, and to prove that they did not discharge those duties. However, according to the Commission experts, AI products make it 'difficult to apply fault-based liability rules, due to the lack of well established models of proper functioning of these technologies and the possibility of their developing as a result of learning without direct human control. ${ }^{60}$ On the other hand, a violation of regulatory AI products requirements may lead to shifting the burden of proving fault, as in Article 2911 of the Czech Civil Code, ${ }^{61}$ Article 6:519 of the Hungarian Civil Code, ${ }^{62}$ Article 1050(1) of the Estonian Law of Obligations Act, ${ }^{63}$ or Article 45 of the Bulgarian Law on Obligations and Contracts. ${ }^{64}$

The most important civil liability institutions of the CEECs regulating the AI liability for damage and personal injury are national civil codes. However, the civil liability institutions of the CEECs are based on regulations that cannot be fully adapted to the new generation of robots that will be equipped with learning abilities and have a certain degree of unpredictability in their behaviours. At present, the responsibility for AI damage may be bore by CEECs' manufacturers, importers, distributors, retailers, operators, designers, owners, users or third parties, but defences are available in each of the CEECs. Moreover, in practice, in the majority of the CEECs the possible concepts of AI liability will be as a defective product, a dangerous thing or a mean of transport. According to the national civil liability institutions of the CEECs, the biggest variety in different concepts of AI liability are found in countries such as the Czech Republic, Estonia, Poland and Slovenia.

It is important to stress the need for implementing, at the EU level, a common standard of care and safety for AI products that will support the EU competitive advantage, the sustainable development of the UE Member States, limit the number of litigations, protect consumers and entrepreneurs, and ensure undistorted competition.

60 European Commission (2019): 23.

61 'If a wrongdoer causes damage to the injured party by breaching a legal obligation, he shall be deemed to have caused the damage through negligence.'

62 'Any person who causes damage to another person wrongfully shall be liable for such damage. The tortfeasor shall be relieved of liability if able to prove that his conduct was not actionable.'

63 'Unless otherwise provided by law, a tortfeasor is not liable for the causing of damage if the tortfeasor proves that the tortfeasor is not culpable of causing the damage.'

64 'Every person is obligated to redress the damage he has faultily caused to another person. In all cases of tort fault is presumed until otherwise proved.' 


\title{
IV. CONCLUSIONS
}

Artificial Intelligence may significantly transform our lives over the next decade. This study examined the possible concepts of AI liability, such as product, thing, wild animal, means of transport, company, agent or legal entity. The outcome of our study outcome suggests that the strict liability regime is dominant in the CEECs, but a fault-based liability regime is also important. However, we were not able to prove that the risk-based liability regime for damage and personal injury caused by AI will provide better protection of consumer and entrepreneurs, and ensure undistorted competition, than the fault-based regime.

Moreover, a meta-analysis of civil liability institutions, such as the Product Liability Directive (EU) and civil codes (CEECs), shows that the current European legal framework is not sufficiently prepared to address the legal issues that will arise when self-driving vehicles or autonomous drones start to operate in fully autonomous mode - without a human in the control loop, and when operating, cause property damage or personal injury. That is why we recommend introducing common regulations of civil liability for damages and personal injuries caused by AI products at the EU level, in order to avoid the distortion of the free movement of AI products between the EU Member States. A common standard of care and safety for AI products may support the EU competitive advantage and sustainable development, and may limit the number of litigations.

\author{
Małgorzata Godlewska \\ SGH Warsaw School of Economics \\ mgodlews@sgh.waw.pl \\ https://orcid.org/0000-0001-7413-0674 \\ Sylwia Morawska \\ SGH Warsaw School of Economics \\ smoraw@sgh.waw.pl \\ https://orcid.org/0000-0001-6708-338X \\ Przemystaw Banasik \\ Gdańsk University of Technology \\ przbanas@pg.edu.pl \\ https://orcid.org/0000-0002-9231-6066
}

Accenture (2016). Why Artificial Intelligence is the future of growth. <https://www.crcom.gov. co/uploads/images/files/4-MarkPurdy\%20-\%20Artificial\%20intelligence\%20and\%20growth. pdf.> [accessed 4 October 2019].

Amiot, M. (2016). Robonomics - How automation will change work. <https://d1iydh3qrygeij.cloudfront.net/Media/Default/email-images/weekly-pick/oct-16/oct7robos.pdf> [accessed 4 October 2019].

Arntz, M., Gregory, T., Zierahn U. (2016). The risk of automation for jobs in OECD countries: a comparative analysis. OECD Social, Employment and Migration Working Papers No. 189. Paris: OECD Publishing. <https://www.oecd-ilibrary.org/social-issues-migration-health/therisk-of-automation-for-jobs-in-oecd-countries_5jlz9h56dvq7-en>. 
Borys, T. (2011). Sustainable development - how to recognize integrated order. Problems of Sustainable Development 6(2): 75-81.

Čerka, P., Grigienè, J., Sirbikytè, G. (2015). Liability for damages caused by artificial intelligence. Computer Law \& Security Review 31(3): 376-389.

Duggal, P. (2017). Artificial Intelligence Law. Kindle Edition.

Lea, G. (2015). Who's to blame when artificial intelligence system go wrong? $<$ https://theconversation. com/whos-to-blame-when-artificial-intelligence-systems-go-wrong-45771> [accessed 4 October 2019].

Lichtenstein, J. (2017). Have You Been Injured by An AI Robot? - European Commission Recommends AI Robots Have Legal Status So They Can Be Sued. <http://www.rightsofcyborgs. com/injured-ai-robot-european-commission-recommends-ai-robots-legal-status-can-sued/> [accessed 4 October 2019].

Maldonado, J. (2018). Legal Ethics: The Ethical Dilemma of Artificial Intelligence. <https://www. natlawreview.com/article/legal-ethics-ethical-dilemma-artificial-intelligence> [accessed 4 November 2018].

McKinsey Global Institute (2013). Disruptive technologies: Advances that will transform life, business, and the global economy. <https://www.mckinsey.com/business-functions/digitalmckinsey/our-insights/disruptive-technologies> [accessed 4 October 2019].

Pagallo, U. (2018). Vital, Sophia, and Co. - the quest for the legal personhood of robots. Information 9(9): 230-241.

Polinsky, A. M., Rubinfeld, D.L. (1988). The welfare implications of costly litigation in the theory of liability. Journal of Legal Studies 17: 151-164.

Schwab, K., Davis, N. (2018). Shaping the Fourth Industrial Revolution. World Economic Forum. Kindle Edition.

The Economist (2018). How Europe can improve the development of AI. <https://www.economist.com/ leaders/2018/09/22/how-europe-can-improve-the-development-of-ai> [accessed 4 October 2019].

Vladeck, D.C. (2014). Machines without principals: liability rules and artificial intelligence. Washington Law Review 89(1): 117-150.

Wong, A. (2017). Who is liable when robots and AI get it wrong? <https://www.theaustralian.com. au/business/technology/who-is-liable-when-robots-and-ai-get-it-wrong/news-story/c58d5dbb37ae396f7dc68b152ec479b9> [accessed 4 October 2019].

\section{CIVIL LIABILITY FOR ARTIFICIAL INTELLIGENCE PRODUCTS VERSUS THE SUSTAINABLE DEVELOPMENT OF CEECs: WHICH INSTITUTIONS MATTER?}

\section{Summary}

The aim of this paper is to conduct a meta-analysis of the EU and CEECs civil liability institutions in order to find out if they are ready for the Artificial Intelligence (AI) race. Particular focus is placed on ascertaining whether civil liability institutions such as the Product Liability Directive (EU) or civil codes (CEECs) will protect consumers and entrepreneurs, as well as ensure undistorted competition. In line with the aforementioned, the authors investigate whether the civil liability institutions of the EU and CEECs are based on regulations that can be adapted to the new generation of robots that will be equipped with learning abilities and have a certain degree of unpredictability in their behaviour. The conclusion presented in the paper was drawn on the basis of a review of the current literature and research on national and European regulations. The primary contribution that this article makes is to advance the current of the research concerning the concepts of AI liability for damage and personal injury. A second contribution is to show that the current civil liability institutions of the EU as well as the CEECs are not sufficiently prepared to address the legal issues that will start to arise when self-driving vehicles or autonomous drones begin operating in fully autonomous modes and possibly cause property damage or personal injury.

Keywords: institutions; civil liability; liability regimes; artificial intelligence; AI liability; CEECs; JEL codes: D02, K13, K15 